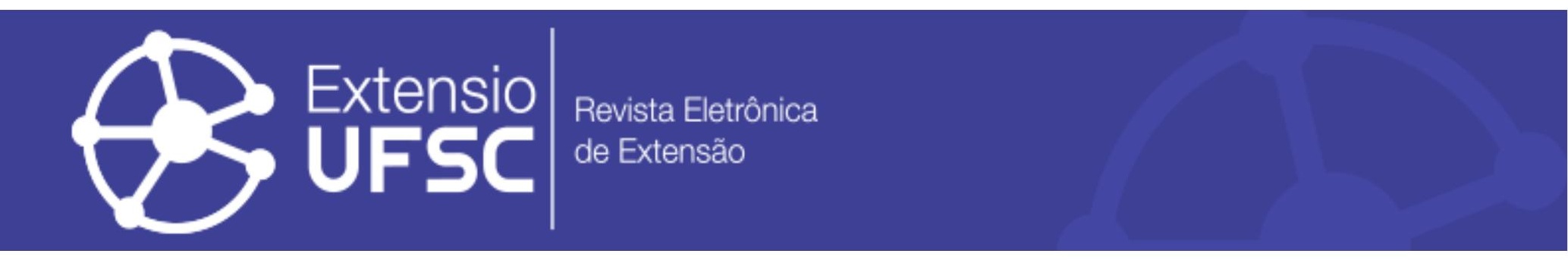

\title{
POLÍTICAS PÚBLICAS URBANAS: FORMAÇÃO DE LIDERANÇAS COMUNITÁRIAS PARA OS CONSELHOS MUNICIPAIS
}

\author{
Alexandre Mauricio Matiello \\ Universidade Federal da Fronteira Sul \\ alexandre.matiello@uffs.edu.br \\ Monica Hass \\ Universidade Federal da Fronteira Sul \\ monica@uffs.edu.br
}

\begin{abstract}
Resumo
O curso de capacitação para lideranças comunitárias "Conselhos municipais de políticas urbanas" teve a finalidade de contribuir para o aperfeiçoamento de lideranças de associações comunitárias, sindicais, de organizações não-governamentais (ONGs) e de estudantes universitários, visando o seu bom desempenho em conselhos de políticas públicas urbanas. Por meio da metodologia de Educação popular, procurou-se capacitar os participantes para a gestão democrática das cidades, de modo a desenvolver competências no que se refere à formulação, acompanhamento e fiscalização quanto às temáticas de planejamento urbano, plano diretor, habitação, saneamento, mobilidade urbana e seu tratamento interesetorial. A incorporação dos temas levou os participantes a refletir sobre sua contribuição na transformação da realidade socioespacial de suas comunidades, percebendo a relação intersetorial das políticas urbanas, e levando-as a serem propositores de uma agenda urbana para o município.
\end{abstract}

Palavras-chave: Participação Social. Conselhos Municipais. Políticas Públicas Urbanas.

\section{URBAN PUBLIC POLICIES: TRAINING OF COMMUNITY LEADERSHIPS FOR MUNICIPAL COUNCILS}

\begin{abstract}
The training course for community leaderships "Municipal Urban Policies Councils " aimed to contribute to the improvement of leaderships of community associations, trade unions, non-governmental organizations and university students, aiming a respectable performance in urban public policies councils. Using the Popular Education methodology, the participants were trained to a democratic management of the cities, in order to develop competences about formulation, monitoring and inspection regarding the themes of urban planning, master plan, housing, sanitation, urban mobility and its intersectoral treatment. The incorporation of those themes made the participants reflect on their contribution to the transformation of the sociospatial reality of their communities, understanding the intersectoral relationship of urban policies and leading them to be proponents of an urban agenda for the municipality.
\end{abstract}

Keywords:Social Participation. Municipal Councils. Urban Public Policies.

\section{POLÍTICAS PÚBLICAS URBANAS: ENTRENAMIENTO DE LIDERAZGO COMUNITARIO PARA AYUNTAMIENTOS}

Resumen

El curso de capacitación para lideres comunitarios "Ayuntamientos de las politicas urbanas" tuvo la finalidad de contribuir para el perfeccionamiento de los dirigentes de las asociaciones comunitarias y sindicales, de organizaciones no gubernamentales y de estudiantes universitarios, con el ánimo de lograr su buen rendimiento en consejos de políticas públicas urbanas. Por la Metodología de la Educación Popular se buscó preparar los participantes para la gestión democrática de las ciudades, con la finalidad de desarrollar aptitud en la elaboración, supervisión y control de proyectos de planificación urbanística, de plan maestro, de vivienda, de saneamiento y movilidad urbana y su tratamiento intersectorial. La incorporación de las cuestiones planteadas hizo que los participantes reflexionaran sobre su contribución en la transformación de la realidad social y espacial de sus comunidades, percibiendo la relación intersectorial de las políticas urbanas, y propusieran una agenda urbana para el municipio.

Palabras clave: Participación Social. Ayuntamientos. Políticas Públicas Urbanas. 
Políticas públicas urbanas: formação de lideranças comunitárias para os Conselhos Municipais

\section{INTRODUÇÃO}

O curso de capacitação para lideranças comunitárias "Conselhos municipais de políticas urbanas" surgiu a partir de uma solicitação feita em 2014 à Universidade Federal da Fronteira Sul (UFFS) - Campus Chapecó-SC pela União das Associações Comunitárias de Chapecó (UNICHAP), visando uma formação para a gestão participativa. Teve-se como objetivo geral deste curso a ampliação dos conhecimentos, das habilidades e das competências de participantes do segmento popular e estudantes universitários nos conselhos gestores setoriais de políticas públicas urbanas (planejamento urbano, uso e ocupação do solo, habitação, saneamento e mobilidade urbana) e seu tratamento interesetorial.

Foram realizadas reuniões entre formadores e líderes comunitários para a definição dos temas, conteúdos e metodologia a serem trabalhados no curso, trocando entre si as experiências vivenciadas pelo segmento popular e acadêmico em fóruns participativos de gestão pública. Por meio da interação dialógica e a troca de saberes, privilegiou-se a abordagem metodológica própria da Educação Popular de forma a subsidiar os participantes a atuarem como multiplicadores, relacionando a sua atuação nos conselhos com a transformação da realidade socioespacial de suas comunidades.

Os conselhos gestores setoriais são instrumentos de representação da sociedade civil na gestão da política urbana. Instituídos a partir da Constituição de 1988, são uma das principais inovações democráticas no campo das políticas públicas, ao estabelecerem espaços de interlocução permanente entre a sociedade política e a sociedade civil organizada (GOHN, 2004). Entre as funções dos conselhos estão: controlar, fazer propostas e contribuir com a gestão pública. Eles não são órgãos executivos nem substituem o parlamento; são uma instância democrática participativa.

Em 2004 foi criado o Conselho Municipal de Desenvolvimento Territorial de Chapecó que possuía 24 representantes sendo: 8 de entidades governamentais, 8 de entidades não-governamentais e 8 representantes das regiões geográficas de planejamento. Estudos feitos sobre este Conselho (KLEBA, et al., 2010; HASS, PADILHA E BORTOLETTI, 2012) demonstram que a participação dos segmentos que representam as comunidades, sindicatos e ONGs é dificultada pelo linguajar predominantemente técnico, o que afasta os segmentos mais populares da possibilidade de interferência efetiva nos temas. 
Políticas públicas urbanas: formação de lideranças comunitárias para os Conselhos Municipais

A Conferência Municipal da Cidade de Chapecó, realizada em julho de 2013, a primeira a acontecer nesta escala desde o surgimento da Conferência Nacional das Cidades em 2003, deliberou sobre a criação de um Conselho Municipal da Cidade, o que acabou sendo ratificado no novo Plano Diretor do município, aprovado em 2014. Seu objetivo é agrupar de maneira intersetorial as políticas públicas de planejamento urbano e uso do solo, de meio ambiente, saneamento, habitação e mobilidade urbana, tratadas até então em conselhos setoriais de políticas urbanas ${ }^{1}$.

Se de um lado abre-se caminho para que o tratamento integrado das temáticas seja mais efetivo para a qualidade das políticas, por outro haverá por parte dos participantes deste novo conselho intersetorial, sobretudo para aqueles do segmento popular, um desafio ainda maior quanto ao domínio dos aspectos técnicos das políticas públicas urbanas. Afinal, será necessário conhecer tanto a respeito de marcos legais, instrumentos urbanísticos e de gestão, quanto da dinâmica espacial do município. Neste sentido, a realização deste projeto de extensão visou a ampliação do conhecimento político e técnico dos participantes no que diz respeito às políticas públicas urbanas bem como procurou fortalecer a participação social voltada para a transformação da realidade socioespacial das comunidades.

No que diz respeito à relação entre extensão e ensino, o princípio da indissociabilidade colocou os estudantes envolvidos com este projeto como protagonistas de sua formação profissional e cidadã, deixando de serem apenas receptáculo de um conhecimento validado pelo professor, para se tornarem participantes ativos do processo (POLÍTICA NACIONAL DE EXTENSÃO UNIVERSITÁRIA, 2013). E este conhecimento adquirido a partir do contato com a realidade retorna por meio do professor e do aluno para a sala de aula. Quanto à relação extensão e pesquisa, o projeto se soma às ações já desenvolvidas pelo grupo de pesquisa "Estado, Sociedade e Políticas Públicas" cujos trabalhos já vem apontando há algum tempo para a necessidade de capacitação dos participantes dos conselhos, sobretudo para os segmentos populares estarem mais empoderados e cientes do papel que desempenham nestes fóruns.

É importante ressaltar que a preocupação com as políticas públicas urbanas estava presente na I Conferência de Ensino, Pesquisa e Extensão (COEPE) da UFFS, realizada em 2010, mais especificamente no fórum temático denominado “Gestão das Cidades,

1 O conselho municipal de Habitação foi criado em 2001, o de Meio Ambiente em 2007 e o Conselho Municipal de Desenvolvimento Territorial, em 2004. Não existem os conselhos de saneamento e de mobilidade urbana. 
Políticas públicas urbanas: formação de lideranças comunitárias para os Conselhos Municipais

Sustentabilidade e Qualidade de Vida", na qual foram definidas as políticas e ações norteadoras para o ensino, a pesquisa e a extensão da UFFS.

Este artigo sumariza o desenvolvimento deste projeto de capacitação apresentando as bases teóricas e metodológicas que fundamentaram o formato do curso dentro da perspectiva da Educação Popular. Também apresentará dados referentes aos participantes, às etapas e conteúdos desenvolvidos na formação e algumas dificuldades para que fosse realizado conforme o planejado.

\section{MATERIAIS E MÉTODOS}

Foram ofertadas 120 vagas no curso de formação, 100 delas disponibilizadas para lideranças comunitárias e 20 para acadêmicos da UFFS do campus Chapecó, sendo que totalizaram 62 inscritos. É importante destacar que o processo de seleção de lideranças foi conduzido pela UNICHAP, prezando por critérios de representatividade geográfica, tipo de segmento (associação comunitária, sindicato, ONG), gênero e faixa etária.

Foi definida uma coordenação acadêmica do curso, bem como uma coordenação externa, representando as entidades e segmentos parceiros do projeto. A partir de reuniões ampliadas, como a que se ilustra na Foto 1, entre coordenação acadêmica, coordenação das entidades e seus representantes, obteve-se por meio da escuta, a sistematização das suas demandas, bem como se desenvolveu a sensibilização para o seu envolvimento na atividade.

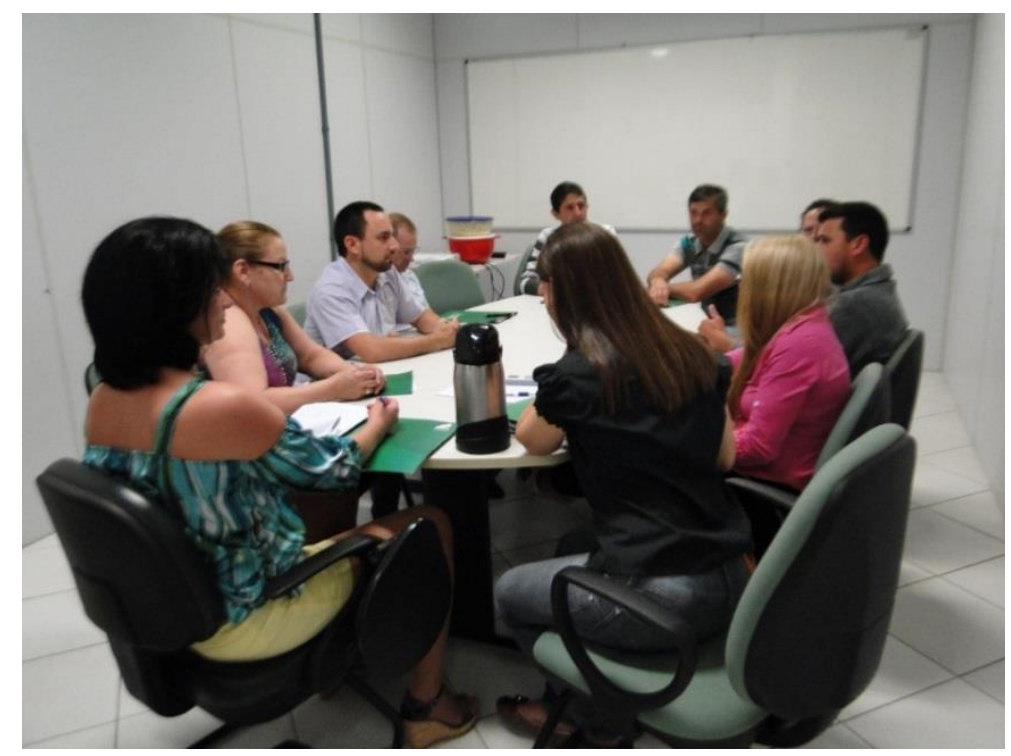

Foto 1: Reunião ampliada da coordenação acadêmica com a coordenação das entidades e representantes das associações comunitárias.

Fonte: Autor 
Políticas públicas urbanas: formação de lideranças comunitárias para os Conselhos Municipais

Os próprios formadores elencados entre professores e pesquisadores nos temas, tanto da UFFS como de outras universidades, precisavam estar imbuídos do espírito da metodologia da educação popular, e embora dominassem os conteúdos, precisavam estabelecer pontes com o público da atividade o qual se tratava em sua maioria de lideranças do segmento popular.

Neste sentido, foi oferecida inicialmente a todos os participantes do curso uma “Formação sobre Metodologia da Educação Popular". Baseada nos princípios freirianos, a Educação popular "visa à organização autônoma e emancipadora dos grupos populares" e "apresenta possibilidades para que sejam desencadeadas ações comprometidas com as causas do povo" de maneira a estimular a tomada de consciência que levem a "libertação, emancipação e participação" como sujeitos integrados no processo (PACHECO JR. \& TORRES, 2009, p. 30).

A Educação Popular norteou a formação dos formadores, com vistas a estabelecer relações com a realidade de vida dos participantes e com a disposição ativa de torná-los protagonistas no processo formativo, com vistas a atuarem futuramente como multiplicadores, como pode-se observar na Foto 2.

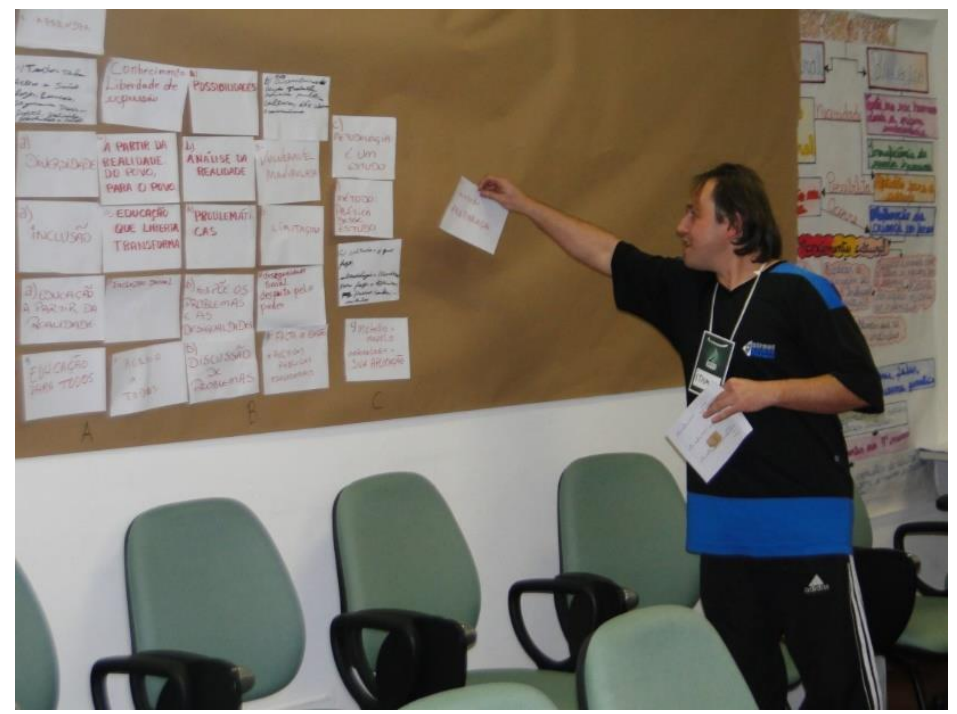

Foto 2: Formação sobre Metodologia da Educação Popular Fonte: Autor

Ressalta-se que a dialogicidade e a problematização constituem categorias centrais da pedagogia freiriana. É a partir delas, materializadas na "pesquisa que ele denomina de investigação temática" (DELIZOICOV, 2003, p. 134) que se buscam identificar os temas geradores os quais se encontram na relação homem-mundo. Por sua vez, a identificação dos temas geradores implica a observação cuidadosa da realidade e das 
Políticas públicas urbanas: formação de lideranças comunitárias para os Conselhos Municipais

significações dadas a ela pelos sujeitos, de modo a captar aí as contradições e as situaçõeslimite que envolvem as pessoas de uma dada comunidade.

Além disso, a investigação temática traduz um processo que é, ao mesmo tempo, pedagógico e conscientizador, ou seja, carrega no seu movimento interno - porque se efetiva no diálogo com "as pessoas do povo". Nos fundamentos freirianos de uma educação popular, "as pessoas do povo" e os grupos populares teriam papel fulcral sobre o "trabalho pedagógico de sua própria tomada de consciência" (BRANDÃO, 2014, p. 60). Por isto, a postura metodológica de condução do processo formativo exige levar em consideração os saberes das classes populares, incorporando suas experiências, e que sempre alerte que estar sensível a sua realidade não permitirá, contudo, apreender exatamente o que relatam (AMARAL \& MONTRONE, 2015).

Organizada, a investigação do tema gerador, por meio de uma metodologia problematizadora, além da possibilidade de apreensão, insere ou começa a inserir os homens numa forma crítica de pensarem seu mundo. Baseando-se em Paulo Freire, esta metodologia preconiza que o educador não é apenas o que educa, mas aquele que, ao educar, promove a transformação da realidade, em uma relação dialética, em uma ideologia emancipadora, em que os educandos se tornem "sujeitos" e não simples “objetos” (BALBINOT; SANTOS \& BRIDI MALLMANN, 2006). Desta maneira, embora os conteúdos e abordagens estivessem "desenhados" de acordo com o perfil esperado para os egressos do curso, também poderiam absorver outros conteúdos e sofrer reformulações por conta dos saberes dos participantes.

A partir das falas das lideranças reunidas em uma das primeiras ocasiões, optou-se por um formato de capacitação que fosse iniciado com uma abordagem mais geral palestra de abertura intitulada "Políticas públicas urbanas e participação: o papel dos conselhos municipais para a Reforma urbana" - seguida de encontros que não superassem a frequência de dois ao mês, devido à condição de trabalhadores e da própria função de liderança que exerciam. Os módulos foram concebidos do geral para o específico, partindo dos marcos legais nacionais até a constituição de políticas na escala municipal, com a participação da coordenação acadêmica e das lideranças fazendo a ponte entre conteúdos ministrados pelos diferentes formadores.

Quatro etapas envolveram o desenvolvimento do curso: Etapa I - Chapecó e seu desenvolvimento urbano; Etapa II - Instrumentos de política urbana; Etapa III - Políticas urbanas setoriais; Etapa IV - Financiamento e gestão democrática. No encerramento foi realizada uma Oficina para resgatar os temas trabalhados na forma de uma agenda de 
Políticas públicas urbanas: formação de lideranças comunitárias para os Conselhos Municipais

pautas, bem como uma avaliação do Curso. Ressalta-se que ao final de cada módulo, constituído de dois encontros, aplicava-se por meio de formulário uma avaliação. Esta incluía a apropriação por parte dos participantes de material didático, o qual prezava pela versatilidade e facilidade de acesso. Na tabela 1, detalha-se o programa do curso, com suas etapas, os módulos e conteúdos a eles relacionados, e a carga horária.

Tabela 1: Formatação do curso

\begin{tabular}{|c|c|c|}
\hline Etapa & Módulo e conteúdo & $\begin{array}{l}\text { Carga } \\
\text { horária }\end{array}$ \\
\hline Palestra de abertura & $\begin{array}{l}\text { Políticas públicas urbanas e participação: o papel dos } \\
\text { conselhos municipais para a Reforma urbana }\end{array}$ & 4 \\
\hline $\begin{array}{l}\text { Formação geral: } \\
\text { metodologia de } \\
\text { educação popular }\end{array}$ & $\begin{array}{l}\text { Educação popular: a pedagogia freiriana como educação } \\
\text { libertadora; o método na teoria freiriana. }\end{array}$ & 4 \\
\hline $\begin{array}{l}\text { ETAPA I - Chapecó e } \\
\text { seu desenvolvimento } \\
\text { urbano }\end{array}$ & $\begin{array}{l}\text { Contextualização do desenvolvimento urbano de } \\
\text { Chapecó }\end{array}$ & 4 \\
\hline \multirow{2}{*}{$\begin{array}{l}\text { ETAPA II - } \\
\text { Instrumentos de } \\
\text { política urbana }\end{array}$} & $\begin{array}{l}\text { Reforma urbana, plano diretor e estatuto da cidade: } \\
\text { princípios e políticas }\end{array}$ & 4 \\
\hline & $\begin{array}{l}\text { Plano diretor e estatuto da cidade: instrumentos } \\
\text { urbanísticos e gestão }\end{array}$ & 4 \\
\hline \multirow[t]{7}{*}{$\begin{array}{l}\text { ETAPA III - Políticas } \\
\text { urbanas setoriais }\end{array}$} & $\begin{array}{l}\text { Política e Plano Nacional de habitação: princípios, } \\
\text { planos e programas }\end{array}$ & 4 \\
\hline & $\begin{array}{l}\text { Plano municipal de habitação: do diagnóstico ao } \\
\text { financiamento (regularização fundiária, zonas especiais } \\
\text { de interesse social, infraestrutura e equipamentos } \\
\text { urbanos) }\end{array}$ & 4 \\
\hline & $\begin{array}{l}\text { Política e Plano Nacional de saneamento: princípios, } \\
\text { planos e programas }\end{array}$ & 2 \\
\hline & $\begin{array}{l}\text { Plano municipal de saneamento: do diagnóstico ao } \\
\text { financiamento (abastecimento de água potável, } \\
\text { esgotamento sanitário, manejo de resíduos sólidos, } \\
\text { drenagem e manejo das águas pluviais urbanas) }\end{array}$ & 2 \\
\hline & Saída de Campo & 4 \\
\hline & $\begin{array}{l}\text { Política e Plano Nacional de mobilidade urbana: } \\
\text { princípios, planos e programas }\end{array}$ & 4 \\
\hline & $\begin{array}{l}\text { Plano municipal de mobilidade: do diagnóstico ao } \\
\text { financiamento (modais de transporte, acessibilidade, } \\
\text { expansão urbana, educação para o trânsito) }\end{array}$ & 4 \\
\hline $\begin{array}{l}\text { Etapa IV- } \\
\text { Financiamento e } \\
\text { gestão democrática }\end{array}$ & $\begin{array}{l}\text { Gestão democrática da cidade: intersetorialidade na } \\
\text { elaboração e gestão das políticas públicas urbanas } \\
\text { (conferências, audiências, consórcios, fóruns, conselhos, } \\
\text { orçamento participativo) }\end{array}$ & 4 \\
\hline $\begin{array}{l}\text { Encerramento: } \\
\text { Oficina (Agenda } \\
\text { urbana de Chapecó) e } \\
\text { Avaliação do Curso } \\
\end{array}$ & $\begin{array}{l}\text { Levantamento das ações prioritárias por parte dos } \\
\text { segmentos populares dentro dos conselhos das cidades } \\
\text { Avaliação do curso }\end{array}$ & 4 \\
\hline
\end{tabular}

Elaboração: Autor 
Políticas públicas urbanas: formação de lideranças comunitárias para os Conselhos Municipais

Os encontros foram realizados nas dependências da UFFS, em horário noturno, procurando-se sempre reunir os participantes em uma forma dinâmica que os envolvesse em trabalhos em grupo, em que pudessem ser estimulados a opinar.

Além desta programação, durante o desenvolvimento do curso foi sugerida pelos participantes uma saída de campo para o contato com a realidade dos bairros da cidade. O roteiro foi em parte elaborado pelos participantes de modo a ilustrar o que haviam indicado durante o curso como problemas em suas comunidades. Em uma das saídas, o foco recaiu sobre as áreas periféricas, como atesta a visita à área de risco de um assentamento irregular na Foto 3.

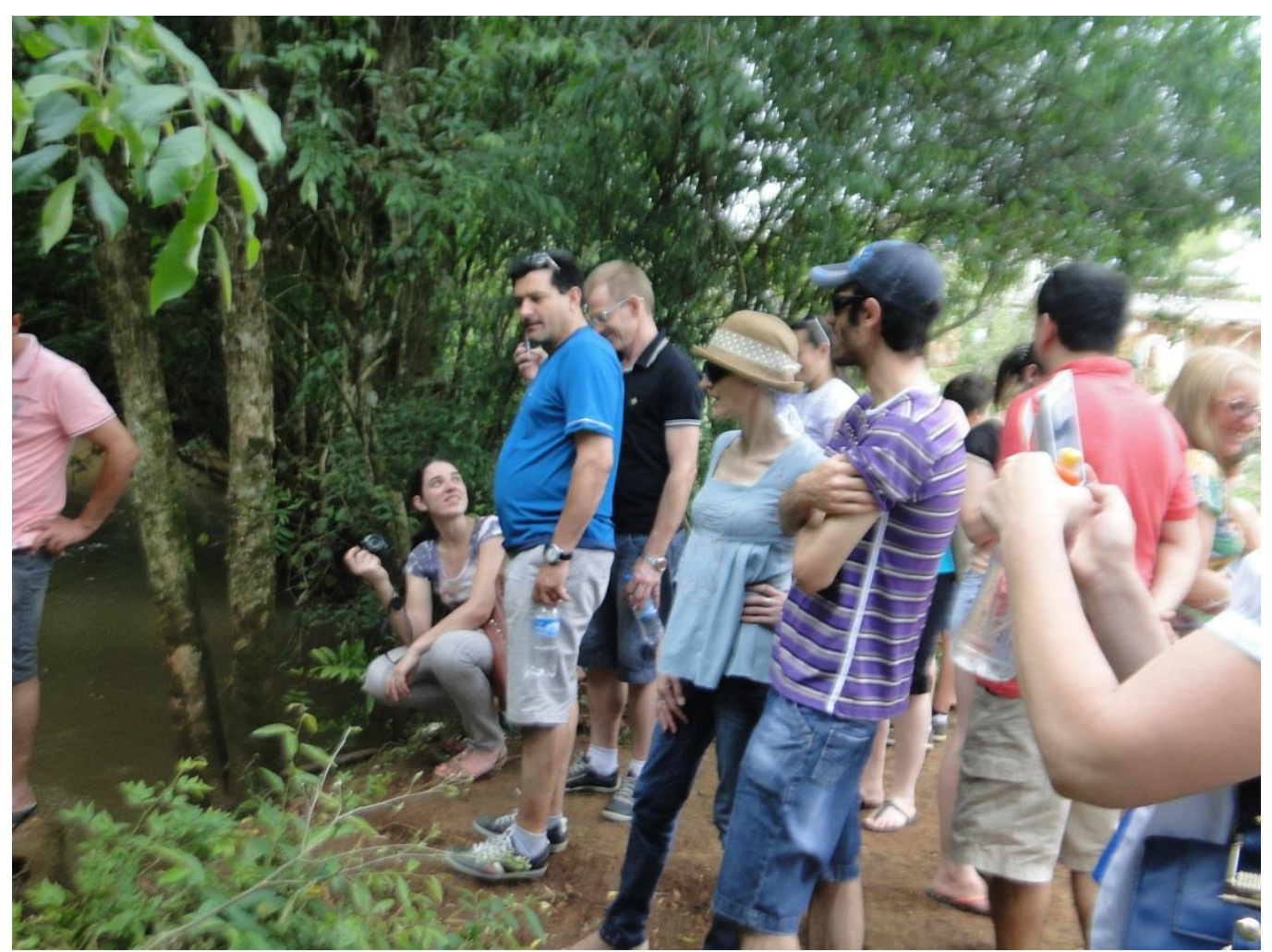

Foto 3: Saída de campo em assentamento habitacional em área de risco Fonte: Autor

\section{RESULTADOS E ANÁLISES}

O planejamento urbano no Brasil vem ganhando mais espaço no debate recente, seja por conta do agravamento das problemáticas nas cidades, seja pela relativa recuperação da credibilidade alcançada pela ação planejadora (MATIELLO, 2007). Horizontes mais alternativos têm apontado para a importância da participação da população nos destinos das cidades Mecanismos participativos que podem ser 
Políticas públicas urbanas: formação de lideranças comunitárias para os Conselhos Municipais

implementados de forma particular como o orçamento participativo, ou outras previstas na Constituição como o caso de conselhos participativos/gestores de políticas públicas são exemplos de alternativas à forma de planejar e gerir as cidades. Neste âmbito, o Estatuto da Cidade (2001) tem importância seminal, marco jurídico que preconiza a gestão ampliada à sociedade na elaboração e implementação de planos diretores.

No mesmo caminho, seguem as legislações e marcos regulatórios das políticas e planos nacionais de saneamento, habitação e mobilidade que também exigem o envolvimento dos mais variados setores no planejamento de ações setoriais de políticas urbanas. Este movimento se contrapõe à prática tecnocrática, verticalizada herdada do Estado centralizador e burocrático, cuja ação sobre a cidade era descolada da realidade local dos cidadãos.

A institucionalização destes canais de participação, como é o caso de audiências públicas, conferências e conselhos nos níveis federal, estadual e municipal mostram a relevância de empoderar os atores para que suas opiniões sejam consideradas nestas instâncias. Santos Jr. (2007) acredita que a participação nestes fóruns pode inclusive dar uma compreensão mais ampla aos atores, apoiando-os num projeto mais amplo de reforma urbana e repercutindo em suas estratégias de luta.

Neste sentido, depreende-se que a participação nos novos canais de decisão a respeito das políticas urbanas constitui uma oportunidade pedagógica para os atores, antes mesmo que o objetivo finalístico ao qual o canal se propõe. Das situações de conflito e enfrentamento de interesses, comuns quando estão na mesma arena segmentos divergentes, vão se forjando lideranças com um intenso poder de intervenção na esfera democrática de planejamento e gestão das cidades.

Maricato (2009, p. 180) ilustra este ganho significativo: "O processo de formulação participativa de um plano pode ser mais importante que o plano em si, dependendo da verificação de certas condições”. Sendo assim, é muito pertinente que a participação nestes canais, especialmente por parte dos segmentos mais populares seja potencializada por meio de uma formação continuada que lhes dê a sustentação técnica para argumentar nos debates e fazer valer suas opiniões.

Foi bastante interessante verificar que durante o processo as temáticas trazidas pelos participantes não diferiam daquelas que vem sendo pautadas nacionalmente. São exemplo disto os efeitos da especulação imobiliária sobre o difícil acesso à moradia pelos mais pobres, a precariedade de infraestrutura de saneamento, abastecimento de outros 
Políticas públicas urbanas: formação de lideranças comunitárias para os Conselhos Municipais

serviços públicos frente a propalada crise financeira dos governos, o estímulo ao automóvel versus a baixa qualidade no transporte público, entre outras temáticas.

Muitos participantes inclusive já haviam se envolvido em processos como a revisão do plano diretor de Chapecó, mas confessaram, contudo, uma dificuldade em compreender os documentos ou leis resultantes, por se traduzirem quase que em uma outra língua, distinta daquela que era usada nos momentos mais amplos de participação. Assim, ainda que tenham se formado no processo de elaboração das políticas e planos, os participantes revelam uma dificuldade em assegurar sua participação efetiva na gestão, sobretudo por uma dificuldade de compreensão técnica. Desta forma, a metodologia da educação popular requer que os conhecimentos do expert sejam traduzidos para o saber leigo, o que no curso pode ser feito por recursos previamente preparados como ilustrações de índices urbanísticos ou por se recorrer a explicações tão logo se percebesse que o conceito ou noção não estivesse sendo apreendido.

Gohn (2000) aponta a necessidade de preencher a lacuna no campo da formação, para que os atores tenham uma participação qualificada para a elaboração e gestão das políticas públicas e destaca que:

\footnotetext{
"É preciso entender o espaço da política para que se possa fiscalizar e também propor políticas; é preciso capacitação ampla que possibilite a todos os membros do conselho uma visão geral da política e da administração. Usualmente eles atuam em porções fragmentadas, que não se articulam (em suas estruturas) sequer com as outras áreas ou conselhos da administração pública” (p. 181).
}

Assim, a capacitação acaba também sendo um lócus privilegiado para o encontro dos diversos segmentos e o tratamento intersetorial das problemáticas urbanas, tal como sequer é realizado no âmbito institucional, o qual pulveriza as demandas e as soluções. Neste aspecto, é válido destacar que o público participante do curso pode perceber o quanto as políticas e ações sobre a cidade se relacionam entre si, podendo inclusive pautar e cobrar na esfera dos conselhos a integração das temáticas. Surpreendia a todos o fato de que as últimas intervenções viárias no município não estivessem associadas ao incremento no transporte coletivo, como é o caso da duplicação do Acesso a BR-282 e o Contorno Viário, destinadas principalmente para o tráfego de automóveis e caminhões.

Também foi reiterado durante o curso que o cotidiano das questões tratadas nos conselhos costuma ser pautado prioritariamente pelo governo municipal. Ao se identificarem como propositores de pauta, os participantes foram capazes de ao final do curso elencar uma série de problemáticas prioritárias, a partir da leitura da realidade local, 
Políticas públicas urbanas: formação de lideranças comunitárias para os Conselhos Municipais

no que chamamos de Agenda urbana de Chapecó, a qual apontava elementos que há muito tempo não vem sendo priorizados nas ações públicas, como por exemplo, a regularização fundiária dos assentamentos.

No aspecto operacional do curso, houve, diante do cronograma, que aconteceu durante um ano eleitoral, a dificuldade de conciliar datas, devido ao perfil militante dos participantes.

No entanto, vale destacar que nenhum dos participantes do curso de capacitação, foi eleito como o Conselho da Cidade em 2015. A escolha para os representantes comunitários no Conselho da Cidade aconteceu em assembleias organizadas nos bairros durante o ano de 2015. Os participantes do curso se dispuseram para as vagas, contudo, revelaram ter sido em geral, uma disputa político-partidária intensa, na qual o fato de terem participado da formação não os colocou em condição de alcançarem as vagas. Foram eleitas lideranças que não necessariamente tivessem algum tipo de formação nas temáticas a serem tratadas no conselho. A UFFS se disponibilizou para ofertar capacitação para os novos conselheiros eleitos, junto à prefeitura municipal, mas o projeto não avançou neste sentido.

\section{CONSIDERAÇÕES FINAIS}

A experiência de capacitação de lideranças comunitárias em políticas públicas urbanas é uma das prioridades propostas pelas Conferências Nacionais das Cidades e pelo Conselho Nacional das Cidades. Em um cenário de gestão democrática, em que os conselhos municipais de políticas públicas têm importante papel na definição e implementação das ações, agentes mais capacitados teriam maior condição de interferir no rumo das políticas.

No caso deste curso, observou-se que a participação expressa nos debates foi fundamental para que os ministrantes compreendessem a realidade a partir das comunidades de origem dos participantes. A metodologia de educação popular foi fundamental para que a teoria estudada fosse relacionada ao cotidiano dos bairros. A incorporação dos direitos - fundamentalmente o direito à cidade - o conhecimento dos marcos legais, a avaliação dos limites e possibilidades dos planos setoriais foram muito importantes para que os participantes tomassem uma visão crítica a partir dos problemas que vivenciam. 
Políticas públicas urbanas: formação de lideranças comunitárias para os Conselhos Municipais

O fator já apresentado, relativo à coincidência do ano eleitoral com o processo de formação e o perfil dos participantes, muitos deles militantes na política, foi um dos que levaram a uma significativa baixa em relação ao número previsto de inscritos. Outro fator foi a dificuldade de conciliar horários e a carga horária extensa do curso pesar na rotina dos participantes, que são trabalhadores, pais e mães de família e ainda líderes ativos na comunidade. Quanto aos estudantes da UFFS, o curso foi oferecido no mesmo horário de aula o que impossibilitou uma maior a participação dos mesmos.

Mesmo com estas limitações, obtiveram certificação no curso 32 participantes com a frequência igual ou maior que $75 \%$, sendo 3 (três) representando conselhos da Igreja Católica, 4 (quatro) conselhos comunitários e municipais, 2 (dois) de pastorais sociais, 8 (oito) de sindicatos, 5 (cinco) de associações, 10 (dez) estudantes da UFFS e demais que não participam de nenhuma organização/entidade específica. Participaram lideranças de quase todos os segmentos propostos, com exceção de ONGs. Os participantes representaram 7 (sete) bairros do município de Chapecó e a maioria deles era do sexo masculino, sendo 30 no total.

Apesar do número de participantes do curso ter sido menor do que o número de vagas previsto, entende-se, a partir do desempenho das lideranças comunitárias nas diferentes etapas da capacitação oferecida pela UFFS que elas possuem capacidade para contribuir nas discussões que envolvem a temática do desenvolvimento urbano na sua comunidade, bem como no Conselho da Cidade.

No entanto, de acordo com a avaliação feita com os participantes na última etapa do curso, a maioria manifesta que ainda não se sente totalmente apta e segura para contribuir de forma mais efetiva nos conselhos municipais e solicita continuidade do curso e aprofundamento em algumas temáticas específicas. Sobretudo devido à complexidade de alguns temas e a necessidade de serem propositivos no que diz respeito a implementação e fiscalização das políticas na área de planejamento urbano, plano diretor, habitação, saneamento, mobilidade urbana e seu tratamento interesetorial.

Para futuros projetos de capacitação, entende-se, a partir da avaliação realizada, que deverá haver uma carga horária maior para o módulo prático de inserção nas comunidades seguido de uma leitura de realidade em campo, com possível diminuição do módulo teórico. 
Políticas públicas urbanas: formação de lideranças comunitárias para os Conselhos Municipais

\section{REFERÊNCIAS}

AMARAL, D. M.; MONTRONE, A. V. G. Educação popular: metodologia de pesquisa como processo educativo. Educação e Contemporaneidade, v. 24, 2015, p. 75-88.

BALBINOT, J.; SANTOS, S.; BRIDI MALLMANN, F. A metodologia problematizadora utilizada pelo enfermeiro na educação sexual de adolescentes. Cogitare Enfermagem, vol. 11, n. 2, mai-agosto, 2006, p. 161-165.

BRANDÃO, C. R. Paulo Freire: a educação, a cultura e a universidade. Memória de uma história de cinquenta anos atrás. EJA EM DEBATE, Florianópolis, ano 3, n. 4. jul. 2014, p. $57-74$.

DELIZOICOV, D. Práticas freirianas e o ensino de ciências. In: MATTTOS, Cauê (org.). Conhecimento científico e vida cotidiana. São Paulo: Terceira/Margem/Estação Ciência, 2003.

GOHN, M. G. M. O Papel dos Conselhos Gestores na Gestão Urbana. In: TORRES, A. C.; RIBEIRO, E. T.(Org.). Repensando a Experiência Urbana na América Latina: questões, conceitos e valores. Buenos Aires: CLACSO, 2000.

GOHN, M. da G. Os conselhos municipais e a gestão urbana. In: SANTOS JUNIOR, O. A. dos, RIBEIRO, L. C. de Q., e AZEVEDO, S. de. Governança democrática e poder local: a experiência dos conselhos municipais no Brasil. Rio de Janeiro: Renan, Fase, 2004.

HASS, M.; PADILHA, A. G.; BORTOLETTI, E. Concepções sobre o desenvolvimento urbano das cidades de Chapecó (SC) e Erechim (RS): os Conselhos de Planejamento Urbano e o Desenvolvimento Sustentável das Cidades de Chapecó (SC) e de Erechim (RS). Relatório de Pesquisa - Edital 002/PROPEPG/UFFS.2012.

KLEBA, M. E. et al. O papel dos conselhos gestores de políticas públicas: um debate a partir das práticas em Conselhos Municipais de Chapecó (SC). Ciência \& saúde coletiva, Rio de Janeiro, v. 15, n. 3, Mai. 2010. Disponível em: $<$ http:/ /www.scielo.br/scielo.php?script=sci_arttext\&pid=S1413-

$81232010000300022 \& \operatorname{lng}=$ en\&nrm $=$ iso $>$.Acesso

em 14 Dez. 2013. http://dx.doi.org/10.1590/S1413-81232010000300022.

MARICATO, E. As idéias fora do lugar e o lugar fora das idéias: planejamento urbano no Brasil. ARANTES, O.; VAINER, C.; MARICATO, E.A cidade do pensamento único: desmanchando consensos. 5. ed. Petrópolis: Vozes, 2009. p. 121-192. 
Políticas públicas urbanas: formação de lideranças comunitárias para os Conselhos Municipais

MATIELLO, A. M. Construção da urbanidade e o (re)desenho da cidade: possibilidades e limites do planejamento urbano a partir do Estatuto da Cidade. In: Anais do VII

Encontro Nacional da ANPEGE, 2007, Niterói. VII Encontro Nacional da ANPEGE: Espacialidades Contemporâneas: O Brasil, a América Latina e o Mundo, 2007.

PACHECO JR, I.; TORRES, M. M. Atualidade do pensamento de Paulo Freire na Educação Popular In: ASSUMPÇÃO, R. Educação popular na perspectiva Freiriana. São Paulo : Editora e Livraria Instituto Paulo Freire, 2009. p. 19-54

POLÍTICA NACIONAL DE EXTENSÃO UNIVERSITÁRIA. Fórum de Pró-Reitores de Extensão das Instituições Públicas de Educação Superior Brasileiras. Porto Alegre: Gráfica UFRGS. 2013.

SANTOS JUNIOR, O. A. Cidade, cidadania e planejamento urbano: desafios na perspectiva da reforma urbana. In: FELDMAN, S.; FERNANDES, A. (orgs.). O urbano e o regional no Brasil contemporâneo: mutações, tensões, desafios. Salvador: EDUFBA, 2007. p. 293-314.

TREVISOL, J.; CORDEIRO, M. H.; HASS, M.(Org.). Construindo agendas e definindo rumos: I Conferência de Ensino, Pesquisa e Extensão da UFFS. Chapecó: UFFS, 2011. 